\title{
Strontium Chromate
}

National Cancer Institute

\section{Source}

National Cancer Institute. Strontium Chromate. NCI Thesaurus. Code C45892.

A yellowish, crystalline, inorg anic compound that emits toxic chromium fumes upon heating. Strontium chromate is highly corrosive and is a strong oxidizing agent. This substance is used as a colorant in polyvinyl chloride, in pyrotechnics, in chrome plating, in aluminum flake coatings, and as a corrosion inhibitor and metal conditioner. Strontium chromate primarily affects the lungs causing shortness of breath, bronchitis, pneumonia and asthma but can also affect the gastrointestinal tract, liver, kidneys and immune system. This substance is a known human carcinogen and is associated with an increased risk of developing lung cancer and cancer of the sinonasal cavity. (NCI05) 